\title{
EL LOGRO DE LA MADUREZ \\ EN LA EDAD ADULTA
}

Luz María Cruz de Galindo

\section{RESUMEN}

La madurez es un objetivo-tendencia que nunca se alcanza del todo. No obstante, en cada etapa de la vida, el ser humano ha de ir logrando ciertas metas - en su desarrollo personal y su capacidad de resolver problemas- que le permitan llegar a una plenitud, cuyo fruto inmediato es la felicidad. En este camino se presentan dificultades, internas y externas que, muchas veces, impiden la realización del proyecto personal de vida.

El presente estudio describe las características generales de la edad adulta, comprendida entre los 30 y 65 años de edad, y los cambios físicos, psíquicos y sociales que se presentan. Asimismo, ofrece algunas propuestas educativas para vivir mejor esta etapa que representa el período más largo de la existencia humana.

Como la edad adulta es muy amplia, se hará énfasis en lo propio de la mediana edad - 40 y 50 años de edad- y en el final de esta etapa, períodos en que, por lo general, se dan cambios bio-psico-sociales significativos.

\section{ABSTRACT}

Mature is an objective that we can never reach at all. Nevertheless, in each period of our lives we can succeed in some of our goals related to our personal development and 
capacity to solve problems, this makes us to be plenty and, in consequence, to be happy. In this way a series of difficulties are presented to us which, most of the time, do not allow us to do our personal life project.

The present study describes the general characteristics of the adult age, between 30 and 65 years, and the physical, psychological and social changes. It also offers some educational proposals in order to bave a better life quality in this period, which represents the largest one of the buman existence.

As the grown up age is too extended, the characteristics of the medium age -40 and 50 years - and the end of this period will be will emphasized, because in this time is when, generally, bio-psycho-social changes are most importants.

: Adultez; etapas de la vida; educación; madurez; plenitud; felicidad; familia; cambios; crisis; intimidad; roles sociales; red social.

\section{INTRODUCCIÓN}

Nuestra sociedad no tiene ritos ni ceremonias para marcar el paso de la adolescencia a la etapa adulta. No existe una única edad para lograr la madurez ${ }^{1}$. De hecho, se es adulto joven en la década de los 20 a los 30 años, aunque algunas personas se hallan cautivas en la adolescencia ${ }^{2}$ y viven su juventud, e incluso su edad adulta, como una adolescencia

Cfr. Hoffman Lois; Paris Scott y Hall Elizabeth., Psicología del desarrollo hoy., Vol. .2, p. 85.

2 Cfr. Castillo, Gerardo., Cautivos en la adolescencia., p. 9. 
prolongada. En este caso, diversas razones - personales, familiares y profesionales - impiden alcanzar la madurez propia de la etapa que se está viviendo.

El concepto de adulto puede estudiarse desde diferentes perspectivas ${ }^{3}$. Cronológicamente y con un criterio sociocultural, esta edad abarca de los 30 a los 65 años. Jurídicamente equivale a ser mayor de edad, momento en que se reconoce al individuo la capacidad de vivir y actuar responsablemente en la sociedad. En Psicología, el término se emplea como sinónimo de madurez y se refiere a la persona que posee plenitud, seriedad y dominio de sí misma. Desde la Sociología, el adulto es aquel sujeto integrado en el medio social, que ocupa un puesto y está en plena posesión de sus derechos, libertades y responsabilidad, siendo por lo general un elemento productivo, aunque no siempre participe en la gestión social. La perspectiva pedagógica considera al adulto como un educando para quien la educación formal deja de ser parte de su quehacer diario - como en la infancia y juventud, donde la escolarización absorbe mucho tiempo-, pero que demanda acciones específicas de educación informal ${ }^{4}$ y no formal, para hacer frente a sus problemas personales y sociales.

3 Cfr. Orduña Allegrini, María Gabriela., La educación para el desarrollo local. Una estrategia para la participación social., p. 110.

4 En la educación informal el aprendizaje aparece como un proceso de ósmosis entre el aprendiz y su entorno. La educación no formal es el conjunto de medios e instituciones que generan efectos educativos a partir de procesos institucionales, metódicos y diferenciados; con objetivos pedagógicos previa y explícitamente definidos; desarrollados por agentes con un rol educativo bien determinado; y que no son parte del sistema educativo graduado o que, siéndolo, no constituyen formas estricta y convencionalmente escolares (Cfr. Orduña Allegrini, Ma. Gabriela., op. cit., pp. 116-117. 
Desde el punto de vista cronológico, la mediana edad comprende las décadas de los 40 y 50 años ${ }^{5}$. Actualmente, por el incremento de las expectativas de vida, en estas edades las personas se encuentran a la mitad del camino, y es importante una actitud positiva y un cuidado personal para recorrer, de la mejor manera posible, el trayecto que aún falta.

De acuerdo con la teoría de Erik Erikson ${ }^{6}$ de las ocho etapas del ciclo de la vida, el desarrollo de un ser humano implica resolver, al menos parcialmente, los conflictos entre las necesidades y las exigencias sociales. En cada etapa existe un conflicto ineludible que la persona ha de afrontar de manera satisfactoria para trabajar con eficiencia en los problemas de la siguiente.

Así, la tarea prioritaria de los jóvenes es el crecimiento de la intimidad, avance que presupone el adecuado desarrollo de la identidad en la adolescencia. La alternativa a la intimidad es el aislamiento. Cuando se resuelve con éxito este conflicto, las personas son capaces de amar en verdad y comprometerse en una relación que exija sacrificio y compromiso. Si el aislamiento domina la intimidad ${ }^{7}$, las relaciones afectivas son frías

5 Un estudio sobre cada una de las décadas de la edad adulta, y de la tercera y cuarta edad puede encontrarse en López de Llergo Ana Teresa, y Cruz de Galindo, Luz María., Quién fui, quién soy, quién seré. Una guia para educar las etapas de la vida., pp. 67 a 129.

6 Aunque la teoría psicosocial de Erikson es aplicable a ambos géneros y a todas las sociedades, él mismo admite que las diferencias culturales influyen en el modo en que se llevan a cabo las tareas del desarrollo en cada etapa. Los investigadores que han realizado estudios longitudinales sobre el desarrollo del adulto, creen que el retrato de Erikson de una personalidad sana sólo puede aplicarse a culturas donde se tiene en gran estima el concepto de individualidad y los roles de los individuos no están estrechamente controlados por la sociedad (Vaillant y Milofsky).

7 Una persona puede tener relaciones sexuales sin desarrollar la intimidad, sobre todo si teme una vinculación más profunda y comprometida. Tal actitud provoca aún más aislamiento y sensación de soledad. 
y poco espontáneas y no hay un auténtico intercambio emocional.

Desgraciadamente, en nuestro mundo es cada vez mayor el número de personas que viven proyectadas hacia fuera, que no se han dado a la tarea de educar su intimidad y, por ello, no saben estar a solas consigo mismas; carecen de espíritu de reflexión y buscan la compañía y el entretenimiento como fines, no como medios, para un armonioso desarrollo de la personalidad. Esto conduce a sociedades infantilizadas cuyos integrantes han perdido la capacidad de amar, con la consecuente amargura e infelicidad.

Según Erikson, conforme las personas se acercan a la mediana edad, han de enfrentarse a una lucha entre la generatividad — capacidad de promover mejoras en la vida personal y en la de otros- y la tendencia a estancarse y encerrarse en sí mismas. La primera supone una preocupación por las generaciones futuras y puede expresarse educando a los propios hijos y guiándolos hacia la etapa adulta; o bien, trabajando con los hijos ajenos en calidad de profesores, médicos, enfermeras o tutores (ayudando a los colegas más jóvenes), por ejemplo.

Pero Erikson ve la generatividad de un modo mucho más amplio que el estar directamente implicado con los jóvenes. Considera que puede expresarse mediante la creatividad y la productividad y, sobre todo, a través de algún beneficio social. La generatividad es el poder que impera en las organizaciones humanas. Las personas que la manifiestan, en cualquiera de sus formas, desarrollan afecto y la fuerza propia de esta etapa de la vida, que incluye la capacidad de empatía y la voluntad de aceptar responsabilidades y de cuidar de otros. 


\section{LO PROPIO DE LA EDAD ADULTA}

\section{Cambios Físicos}

Durante la mediana edad, los cambios corporales exigen la modificación de algunas actividades - personales, intelectuales, sociales-y pueden determinar el tipo de empleo, pasatiempo, alimentación, etcétera. No todos los cambios físicos en esta edad son procesos normales de envejecimiento; algunos se deben a enfermedades; otros, a excesos relacionados con el consumo de tabaco, alcohol, drogas, una mala nutrición, estrés, etcétera; y otros, al abandono.

La menopausia, que supone el fin de la capacidad reproductora de las mujeres, en muchos casos no crea trastornos demasiado graves. Los hombres sanos de mediana edad conservan su capacidad reproductora aunque, en ocasiones, su respuesta sexual es más lenta (a veces como resultado de factores psicológicos). Sin embargo, a pesar de los cambios físicos y hormonales, la mayoría de las personas sexualmente activas puede continuar estas actividades incluso a una edad muy avanzada.

Los hechos sociales como la jubilación, el mudarse de casa y la viudez pueden tener efectos negativos sobre la salud. Por increíble que parezca, cambiar de residencia a menudo provoca más tensión que los otros dos.

Durante la mediana edad, las personas empiezan a notar modificaciones en el aspecto y funcionamiento de sus cuerpos. Todos los pequeños cambios que se manifestaron a principios de la etapa adulta han ido progresando paulatinamente y les fuerzan a darse cuenta de que ya no son jóvenes. La 
experiencia es desestabilizadora y conduce a que muchos miren atrás deseando recuperar la apariencia y el vigor de la juventud. El rostro tiene claramente algunas arrugas, la piel ya no se estira tan firmemente, el pelo comienza a ponerse canoso; los músculos pierden fuerza o rapidez, debido a que la masa muscular empieza a encogerse tras cumplir los cuarenta. Sin embargo, al menos parte de este encogimiento, puede ser resultado de una vida más sedentaria. Los trastornos crónicos —obesidad, hipertensión, artritis, diabetes—se hacen presentes.

En una cultura que sobrevalora la juventud, es comprensible que las mujeres y hombres de mediana edad se sientan inconformes respecto a su apariencia física. No obstante, el proceso de deterioro es paulatino y, por ello, las consecuencias son irrelevantes en la vida cotidiana de los adultos, quienes, de alguna manera, aprenden a compensar las aún poco significativas pérdidas. De hecho, la mayoría de las personas entre los 40 y 65 años parecen y se sienten más jóvenes y sanas actualmente, que sus padres y abuelos a esa edad.

Los datos acerca del estado de salud muestran que, en los hombres, la tasa de mortalidad es más alta y tienden a contraer enfermedades crónicas; las mujeres presentan condiciones agudas y son hospitalizadas con más frecuencia. La buena nutrición, el ejercicio, la disminución en el consumo de alcohol, el dejar de fumar y evitar los rayos directos del sol pueden retardar muchos cambios esperados en la salud y el aspecto.

\section{Cambios Psiquicos}

Los cambios cognoscitivos en los adultos se desarrollan lentamente, no siempre son predecibles y su ritmo es variable. 
Según Gisela Labouvie-Vief, durante la mediana edad empieza a florecer una etapa de pensamiento complejo, el "posformal" ${ }^{8}$. Las experiencias de la vida y un entorno social cada vez más complicado, llevan a los adultos a integrar el pensamiento objetivo y analítico — formal ' - con el subjetivo y simbólico. Este estilo integrativo es menos literal y más interpretativo e implica la aplicación de operaciones a sistemas diferentes y sus interrelaciones.

Warner Schaie propone una teoría de etapas para la inteligencia del adulto que relaciona la cognición con las tareas del desarrollo. Su enfoque es compatible con el sistema de Erikson y, debido a la gran variabilidad en la cognición del adulto, sus ciclos no están perfectamente definidos. Según Schaie, los cambios cognitivos que tienen lugar en la infancia y la adolescencia ("etapa adquisitiva") reflejan modos cada vez más eficientes de adquirir nueva información; los cambios posteriores, evidencian los modos de emplearla.

En la juventud — segunda etapa de Shaie- se dan los logros. Entonces se han de aplicar los conocimientos acumulados durante años; las consecuencias de la resolución de problemas pueden ser determinantes cuando se refieren a decisiones como elección de estado o de profesión. Este momento prepara a los jóvenes a las etapas cognitivas de la

${ }^{8}$ El razonador posformal puede establecer relaciones, análisis y síntesis novedosas; por ejemplo, se da cuenta que los seres humanos y las cosas poseen características aparentemente contradictorias: una persona puede ser amorosa y fría; generosa y tacaña; débil y fuerte...

9 El pensamiento formal es consciente, lógico, abstracto y, supuestamente, con pocos rasgos de emoción, intuición o imaginación. 
mediana edad: la responsable y la ejecutiva ${ }^{10}$. En la primera, las personas buscan resolver los problemas prácticos de la vida y cumplir sus obligaciones con los miembros de la familia y sus compañeros de trabajo. En la segunda - que no aparece necesariamente-, la responsabilidad se proyecta a la comunidad o a asuntos nacionales e internacionales. Ahora los adultos están ocupados en dirigir organizaciones, y se preocupan por la promoción del bien común ${ }^{11}$.

La "etapa ejecutiva" es síntoma de madurez social que, de acuerdo con José Pérez Adán ${ }^{12}$, se relaciona con la conciencia cívica, expresada en la participación sociopolítica - cuya concreción es el número de horas dedicadas, per cápita, a actividades sociales no remuneradas- Tal conciencia es, para el autor citado, un Índice Relativo de Salud Social (IRSS), y será una realidad si, en las distintas comunidades, se educa a la niñez y a la juventud en actitudes de servicio y participación.

La mayoría de las investigaciones sobre el desarrollo intelectual del adulto, explora la inteligencia psicométrica o la práctica. La primera, a través del rendimiento en los exámenes de coeficiente intelectual, utilizando tareas simples donde se ha de recurrir a la memoria, cálculo, comprensión y resolución de problemas. La segunda se refiere a la adaptación al

Según Shaie, en la tercera edad se da la etapa reintegrativa. Ahora la exigencia de adquirir conocimientos ha disminuido y las consecuencias de tomar decisiones tal vez no resulten tan definitivas. Algunos adultos mayores, en vez de abarcar problemas ocupacionales, asuntos familiares, de la comunidad o de la nación, se centran en una sola área.

${ }^{11}$ El paso de una etapa a otra no sólo está determinado por la edad, sino también por las tareas del desarrollo.

${ }_{12}$ Cfr. La salud social. 
entorno como proceso activo que dura toda la vida. Se trata de una perspectiva contextual en donde la inteligencia se demuestra por la aplicación del conocimiento, la maestría y la experiencia en los problemas cotidianos. El modelo de proceso dual recurre a ambos métodos y mide la inteligencia a través de los exámenes psicométricos o de las habilidades cristalizadas ${ }^{13}$.

De hecho, el desarrollo intelectual del adulto presenta:

- Declive en los mecanismos básicos, que pueden compensarse parcialmente con la práctica.

- Mejora en el rendimiento, con motivación.

- Optimización selectiva, que minimiza las pérdidas en el rendimiento.

Los adultos resuelven problemas prácticos de la vida adaptándose a las circunstancias, organizando sus respuestas en términos de los siempre cambiantes factores del momento, y de sus propias metas y conocimientos. El pensamiento que utilizan depende de un acervo de conocimientos generales, experiencias y habilidades. Si su empleo les exige actividades intelectuales, es posible que aumente su agilidad mental.

También la personalidad y estilo de vida pueden afectar el funcionamiento de la inteligencia. Los adultos con intereses intelectuales, ubicados en entornos estimulantes, tienden a conservar un alto nivel de rendimiento; los que se retiran de

${ }^{13}$ Inteligencia cristalizada: incluye las aptitudes orales y el conocimiento mecánico, y refleja la capacidad de manejar información bien aprendida en situaciones familiares. Estas habilidades se enseñan en la escuela y la cultura las enfatiza. 
la vida activa, suelen mostrar declives. El estado físico óptimo propicia tiempos de reacción más rápidos, mejor memoria y mayor capacidad de razonamiento. De ahí la importancia de promover entre la población adulta actividades educativas que les permitan aprender más de su actividad profesional; adquirir cultura; contar con momentos de recreación y esparcimiento; y favorecer la socialización.

\section{Cambios de Roles Sociales}

En nuestra sociedad, ser de mediana edad implica pertenecer al grupo dirigente, el que está al mando y detenta la responsabilidad ${ }^{14}$. Tales años se caracterizan por la preocupación en expandir y evaluar la propia adultez y, a veces, por comenzar una nueva vida. Cuando las personas llegan a esta edad, la mayoría encuentra que sus energías se dirigen a temas distintos ${ }^{15}$. Es posible que preparen la vejez que se acerca, y empiecen a pensar, con más frecuencia, en la realidad de la muerte. Además, pueden tener la sensación de que les faltará tiempo y recursos para realizar todos sus proyectos $\mathrm{y}$ aspiraciones.

No obstante, algunos adultos de entre 40 y 50 años de edad — debido a la emancipación tardía de los jóvenes, el retraso de su inserción en el mundo laboral, la edad en que contraen matrimonio y la deliberada espera para procrear hijos- se encuentran en una etapa más prematura del desarrollo

${ }^{14}$ Desde luego, esto no sucede en comunidades marginadas donde la ignorancia y la pobreza extrema propician el envejecimiento prematuro y unas condiciones de vida infrahumanas.

${ }^{15}$ Sin embargo, algunos intereses y cambios se relacionan más con las circunstancias de la vida que con la edad cronológica. 
familiar que los de generaciones anteriores. Esto fenómeno es muy acentuado en Estados Unidos y Europa, aunque en nuestro país cada vez se presenta con más frecuencia. Además, por la mejora en las condiciones generales de salud de la población, es común que los padres de estos adultos aún vivan y haya un menor número de viudas. Esto provoca importantes cambios en la dinámica familiar y social, afectando especialmente a las mujeres que trabajan fuera de su hogar, y tienen la responsabilidad del cuidado de niños pequeños y de padres en la tercera o cuarta edad. Tal situación puede traer problemas que van, desde el descuido de importantes obligaciones, hasta un estado de agotamiento y ansiedad por exceso de trabajo intra y extra doméstico, pasando por conflictos conyugales, laborales, etcétera. Habrá de transcurrir más tiempo para valorar las consecuencias de un fenómeno que no se consideraba con frecuencia en generaciones anteriores.

Durante esta edad, se presentan acontecimientos que llevan a modificar algunos hábitos, ajustarse a nuevas condiciones, buscar nuevos amigos o transformar el estilo de vida. Casarse, tener un hijo, mudar de trabajo... son hechos que provocan tensión y es necesario adaptarse a ellos. Además, la vida cotidiana puede verse ensombrecida por una enfermedad grave, un trastorno de tipo emocional, un divorcio o una experiencia muy decepcionante con un hijo. Cuanto mayor sea el número y severidad de estos cambios y experiencias, tanto mayor será el grado de tensión que repercute, a su vez, en lo físico, psicológico y espiritual.

Cuando se prevé un acontecimiento y se considera parte normal del curso de la vida, éste provoca menos estrés que cuando es inesperado, extemporáneo o no sucede y, por ello, 
entra en conflicto con el "reloj social" ${ }^{16}$ de cada persona. Dos factores ayudan a hacer frente a los distintos sucesos: a) esperarlos, pues esto permite prepararse y buscar la mejor manera de asumirlos; b) darse cuenta de que otras personas atraviesan por situaciones semejantes y es posible vivir con ellas la recíproca comprensión y solidaridad. Además, algunos cambios inesperados en la mitad de la vida no siempre son malos, aunque a primera vista así lo parezcan, e incluso pueden desencadenar un crecimiento positivo.

En muchas sociedades, los actuales adultos de mediana edad — en comparación con los de épocas pasadas - tienen mejor educación y más mujeres disfrutan de un empleo remunerado; saben utilizar estrategias maduras para resolver los problemas personales y asumir responsabilidades, y dan muestras de mayor realismo sobre sus puntos fuertes y débiles ${ }^{17}$ (aunque vale la pena insistir que este tipo de situaciones no se refieren a personas de comunidades que viven en pobreza extrema, donde se presentan problemas que rebasan los límites de este estudio).

El paso de la adolescencia a la edad adulta, implica el desempeño de nuevas tareas familiares y de trabajo. Las primeras se presentan —en las personas casadas — al nacer los hijos, cuando éstos entran a la escuela, se convierten en adolescentes, abandonan el hogar... La crianza de los hijos incrementa las

${ }^{6}$ Criterios para juzgar la propia conducta y la de los demás en términos de pronto, tarde o a tiempo.

17. La salud mental en la mitad de la vida depende, en gran parte, del binomio entre lo que una persona tiene y lo que espera conseguir. Sin embargo, aunque la diferencia fuera demasiado grande, es posible desarrollar cierta tolerancia a la frustración, y seguir adelante. 
responsabilidades, pero que esto se considere un factor de tensión, depende de la disponibilidad de recursos y los requerimientos de tiempo de otras obligaciones, sobre todo laborales. En realidad, para la mayoría de los adultos, esa crianza trae consigo notables estímulos.

Las responsabilidades laborales absorben gran parte de las vidas de hombres y mujeres y, generalmente, la conformidad con el empleo aumenta durante la edad adulta. Combinar las obligaciones de trabajo con las familiares es una tarea compleja en muchos matrimonios $y$, en ocasiones, como se ha dicho, las sobrecargas las padecen las mujeres, quienes, cuando trabajan fuera del hogar realizan, en promedio, aproximadamente dos terceras partes del cuidado de los hijos y de los quehaceres domésticos, además de contribuir al ingreso familiar. Son ellas quienes, con frecuencia, asumen la responsabilidad de cuidar a dos generaciones al mismo tiempo.

Las necesidades de los padres que envejecen pueden causar graves presiones en el futuro a las mujeres de mediana edad, muchas de ellas comprometidas con sus trabajos. Además, un número cada vez mayor de adultos de estas edades no tendrá hermanos que le ayuden a compartir los cuidados; y la paternidad retrasada mantendrá más tiempo a los hijos en el nido.

Por otra parte, la cada vez mayor inserción del varón en la vida familiar ha originado un replanteamiento de los roles masculinos y femeninos dentro de la sociedad doméstica. Existen casos en que la mujer prácticamente asume las responsabilidades económicas, y el marido colabora en las tareas del hogar en forma significativa. Las consecuencias - positivas 
y negativas - de tales cambios se advertirán en las nuevas generaciones.

Suele creerse que el período en que los hijos abandonan el hogar es especialmente doloroso, sobre todo para las mujeres. Si una mujer se había definido a sí misma por su papel como criadora de hijos, podría esperarse una nueva crisis de identidad y una terrible sensación de pérdida: es el "síndrome del nido vacío". Pero esto no sucede siempre. Cuando los hijos abandonan el hogar, varios factores afectan las reacciones de los padres: el momento en que lo hacen; la velocidad con la que sucede - si todos los hijos se van casi al mismo tiempo-; la propia relación de los progenitores; de las madres con los hijos y la situación profesional de éstas. El problema se agrava si los hijos se van demasiado pronto, como los que se escapan a los 15 años. No obstante, también puede ser fuente de graves desavenencias que el hogar no se vacíe en el momento adecuado o que vuelva a llenarse cuando los hijos mayores regresan al hogar, por problemas con su recién fundada familia o conflictos de tipo laboral.

Por otra parte, los ciclos normales de vida familiar ya no ocurren en muchas vidas adultas, por la incidencia del divorcio y del segundo matrimonio, y por el incremento de los que no se casan.

Todos estas situaciones se relacionan con el desempeño de roles sociales, pero la personalidad es más que eso. Existen cualidades y diferencias temperamentales persistentes en la forma en que las personas afrontan sus problemas; y cambios sistemáticos en el modo de ser, durante los años adultos (como la madurez personal). El punto clave es si, en este período 
pospaterno, la relación marital es rica o no lo es, y ello depende de que los esposos hayan pasado -individual y conjuntamente- a niveles más maduros en el desarrollo personal. De hecho, la satisfacción marital está, por lo general, en su nivel más alto inmediatamente después del matrimonio y en el período pospaterno ${ }^{18}$.

\section{HACIA LA MADUREZ}

Es lamentable que algunos adultos ${ }^{19}$ imiten a los jóvenes en muchas actitudes y comportamientos, y confundan la juventud de espíritu con la falta de compromiso; la espontaneidad con la autenticidad; la trivialización de la responsabilidad con la genialidad; el tiempo con la "instantaneidad" y el deber con el placer. Tales actitudes resultan mucho más graves en los adultos que en los jóvenes, porque de los primeros se espera que sean modelos de conducta y guías de las siguientes generaciones, y no ejemplos poco edificantes.

La madurez que se pide a un adulto implica direccionalidad, integración, actitudes adecuadas, continuidad en la trayectoria biográfica, estabilidad personal. No es una mera respuesta biológica y emocional sino, sobre todo, la capacidad de la persona de someter sus impulsos, deseos y emociones a la ordenación de la razón — a la luz de su entendimiento y a la decisión de su voluntad- para gobernarse a sí misma con buen juicio y prudencia. Además, esta madurez no se prueba

${ }^{18}$ La mengua en la satisfacción marital durante los años de educación de los hijos puede ser causada por la multiplicidad de papeles, o bien por tensiones económicas y de trabajo.

19 Cfr. Polaino-Lorente, Aquilino., Madurez personal y amor conyugal., pp. 9 a 30. 
en un instante, ni está vinculada sólo a una situación singular, es una tarea vitalicia y que siempre puede optimizarse.

Parte esencial de la madurez es la capacidad de asumir proyectos, lo que no sólo significa elaborar un plan según el cual se disponga lo que todavía no se ha hecho y está por hacerse. Aquilino Polaino asegura que: "Tiene un proyecto quien, con ideales bien concebidos, es capaz de vertebrar su propia existencia de acuerdo con una forma de vida por la que libérrimamente se ha optado". No obstante, es necesario que el proyecto sea valioso.

Una persona sin proyecto es una persona vacía, siempre pronta a escapar del mundo y a huir de sí misma, alguien que hizo del miedo su morada, ha dejado sus compromisos y ha querido refugiarse en el consumismo hedonista, en el instante placentero, en la droga o en el sexo y, de todas maneras, ha quedado insatisfecha. La solución, más que huir, es "correr" hacia sí misma, hacia su intimidad y buscar hacer vida sus convicciones para transformar el mundo y sus circunstancias, lograr sus metas y cumplir sus compromisos. El fantasma de la inmadurez personal puede surgir no sólo por el desconocimiento de uno mismo, sino también por la ignorancia de los otros. Esto dificulta, respectivamente, la capacidad de donación y de aceptación del otro.

Como ninguna persona es una isla, en todo comportamiento humano hay una dimensión social que implica el establecimiento de lazos interpersonales y solidarios. Tal dependencia es necesaria y buena. Alguien radicalmente independiente sería quien nunca eligió, ni elige, ni elegirá nada, quien no ha establecido vínculos y ha renunciado a todo, salvo a la nada de su no elección. 
Así, la personalidad se desarrolla bien cuando el ser humano, con todas sus predisposiciones, interactúa con el entorno y se enfrenta a distintas tareas ${ }^{20}$. Al llegar a la mediana edad, la mayoría cree que su modo de ser ha cambiado mucho desde la adolescencia, en general, a mejor; ha adquirido un mayor sentido de mando de su propia vida - pese a las humanas limitaciones- y quizá se interese más por el bienestar de las generaciones posteriores.

Una forma de evaluar la madurez es relacionarla con la habilidad de hacer frente con éxito a los acontecimientos y decisiones que se presentan a la mayoría de las personas en momentos especiales de su vida. En términos de la teoría de Erikson — que ya se ha mencionado- la madurez, en la juventud, incluiría una resolución satisfactoria de las tareas del desarrollo de la niñez y la adolescencia, la capacidad para comprometerse en una relación estrecha con otra persona -intimidad-, la preocupación de guiar a la próxima generación y el llevar a cabo un trabajo productivo.

En especial, a partir de la edad adulta, la madurez supone un ajuste continuo a expectativas y responsabilidades siempre cambiantes. Con frecuencia existe una tormenta personal durante esta etapa. Sin embargo, es posible afrontar los cambios en forma adecuada y ejercer una buena y productiva influencia en el entorno. Una vez que se han resuelto - en la medida de lo posible - las incertidumbres sobre el futuro, la vida se suaviza.

Para algunos (Levinson y Gould), la "crisis de la mitad de la vida" es un estado de sufrimiento físico y psicológico que surge

${ }^{20}$ Puede decirse que las tareas de la edad adulta son trabajar y amar. 
cuando las tareas del desarrollo amenazan con desbordar los recursos internos y el sistema de apoyo social de una persona. Sin embargo, la mayoría de los estudios todavía no ha descubierto una crisis general en esta edad. Es cierto que algunas personas pasan crisis durante los 40 , pero no más que las de que tienen 20, 30, 50 ó 60 años.

No obstante, el modo de responder a los retos y cambios - esperados o no- influye en cómo se siente la persona consigo misma. El estrés puede ser inevitable durante la mediana edad, pero de por sí no produce una baja en el autoconcepto ni en la autoestima. El sentido del "yo" sigue firme cuando, quien padece estrés, puede aliviarlo o soportarlo; cuando, ante la derrota, es consciente de su valor como persona, mantiene buenas relaciones con los amigos y la familia, y enfrenta retos en forma satisfactoria.

La madurez en la edad adulta tiene que ver con la educación recibida, la clase social a la que se pertenece y las exigencias de trabajo. Los adultos con empleos y papeles complejos pueden resolver los conflictos. Por ello, un desafío para nuestra sociedad mexicana es generar fuentes de trabajo adecuadas y educar bien a niños y jóvenes para que, al llegar a la edad adulta, posean una madurez personal que favorezca la madurez comunitaria.

Todo ello presupone el conocimiento de las propias habilidades y limitaciones, y la capacidad de establecer con otros un intercambio de intimidades a través de la amistad; de aceptar y dar amor; de responder sexualmente en forma adecuada; de entregarse a los demás; realizar un trabajo productivo y cultivar las más variadas relaciones sociales. 
Como se ha mencionado, el trabajo ocupa un lugar primordial en esta etapa y su influjo abarca casi todos los aspectos de la vida de un ser humano, define su posición en la sociedad y, cuando llena sus aspiraciones y expectativas, proporciona una actividad satisfactoria, un medio de expresión de la creatividad y el sentido de pertenencia a un grupo determinado.

El sentido de pertenencia tiene que ver con la idea de "red social", del conjunto de relaciones de cada persona con su familia y amigos. Robert Kahn y Toni Antonucci hablan del "Convoy" como una red social que acompaña a lo largo de la vida; las relaciones familiares casi siempre son persistentes y algunas amistades pueden durar décadas. Estas redes dan un apoyo social formado por una compleja combinación de afecto, seguridad y ayuda.

Indudablemente, uno de los elementos claves que diferencian a aquellos adultos que vencen los obstáculos de la vida con facilidad, de quienes no lo bacen, son los lazos que ban creado y mantenido. El número mínimo de vinculaciones ${ }^{21}$ genuinamente centrales requeridas para la salud y el desarrollo es uno: un confidente, una relación marital satisfactoria, un amigo... parece ser la necesidad básica irreductible. Quienes carecen de ello, están más propensos a enfermarse, a morir pronto y a presentar problemas emocionales ${ }^{22}$. Y, quienes

${ }^{21}$ La teoría de la vinculación es útil para describir tanto las relaciones amorosas como las inevitables desvinculaciones de la madurez: la muerte de algún familiar, de los amigos, el divorcio u otras pérdidas.

${ }^{22}$ La falta de una relación de este tipo es lo que Antonio Royo Marín llama la soledad del corazón. Se trata de “(...) la soledad total y definitiva del que no tiene absolutamente a nadie en este mundo que pueda acompañarle o consolarle en su dolor (...). Es la orfandad total, absoluta, definitiva, sin ninguna esperanza por muy remota que seaw. Nada te turbe, nada te espante., p. 50. 
sólo tienen una de tales relaciones, corren un riesgo mayor de tener problemas si pierden a esa persona.

Existe una diferencia cualitativa entre el tipo de apoyo que los adultos reciben de los miembros de la familia y del recibido por parte de los amigos. Si consideramos los tres elementos básicos de solidaridad social —afecto, seguridad y ayuda - es posible que la familia (padres, abuelos, hermanos) sea la fuente primaria de ayuda, en tanto que los amigos proporcionan afecto y seguridad.

La vinculación central para un adulto es normalmente un esposo (a). Con el tiempo, la mayoría de los matrimonios parecen volverse menos plenos, menos vitales. Aquellos que siguen siendo satisfactorios, sin embargo, son los caracterizados por encuentros más positivos, una mejor interpretación de las señales del otro y una resolución de los conflictos menos agresiva y más íntima.

Las relaciones con los otros miembros de la familia - hijos grandes, padres, hermanos y familiares lejanos- permanecen fuertes durante la edad adulta, con un contacto frecuente. Para la mayoría de los adultos, tales contactos parecen surgir del placer, no de la obligación. Los tipos de ayuda y asistencia brindados a los miembros de la familia o recibidos de ellos, cambian durante el ciclo de la vida familiar. La generación intermedia, con hijos adultos y padres ancianos, brinda más ayuda de la que recibe. Otros grupos tienden a recibir más de lo que dan.

Los amigos se seleccionan con base en las afinidades y se mantienen debido a la semejanza continua y a la reciprocidad 
percibida. El mayor número de amigos y las amistades más íntimas parecen presentarse en los primeros y últimos años de la edad adulta. El nivel más bajo está en el punto intermedio o madurez, tal vez como resultado de concentrar la energía en el núcleo familiar y en los papeles de trabajo durante estos años. Esta red social tan importante en la vida de todo ser humano, se fortalece en forma considerable con la presencia de los abuelos.

\section{FRONTERA ENTRE LA EDAD ADULTA Y LA TERCERA EDAD: CUANDO LAS PERSONAS SE CONVIERTEN EN ABUELOS}

Los abuelos jóvenes ${ }^{23}$ están ubicados en la "dimensión temporal" de varias familias: la suya, la de sus hijos y, quizá un poco menos, en las familias de origen de sus nueras y yemos. De hecho, con el incremento de la esperanza de vida y el descenso de la fertilidad, ha aumentado, en forma considerable, el número de familias en las que están presentes varias generaciones, pero hay menos personas en cada una de ellas.

Las preocupaciones de estos abuelos, respecto a los hijos, son múltiples: dificultades profesionales, elección de estado, noviazgos, fundación de una nueva familia... En cuanto a sí mismos, cambian sus circunstancias laborales, sus condiciones de salud, etcétera. Todo esto supone una reorganización de ayudas y relaciones familiares más amplias, con nuevos problemas y posibilidades.

${ }^{23}$ Cfr. Oliveros F. Otero y Altarejos, José. Los abuelos jóvenes., pp. 35 a 44. Según estos autores, un abuelo joven es capaz de aprender de toda relación humana, de toda situación y de dar más de sí mismo. Cronológicamente abarca la década de los 50,60 y tal vez la primera mitad de los 70 , aunque esto es variable. 
Del modo de vivir de un abuelo, de convivir, de trabajar; de su preparación en distintos órdenes de la vida, de su capacidad cultural diferente, resultará una dotación — fruto de cada biografía personal- que habrá de ponerse al servicio de la familia extensa, en especial de los nietos.

El trato con los nietos adquiere distintos matices: desde el simple compañerismo - en la cual hay convivencia, pero no corresponde a los abuelos, directamente, la tarea de educar a los nietos- hasta una cercanía que resulta enriquecedora para ambas partes, y en donde los primeros tienen una injerencia importante en la vida de los segundos; o bien, la casi total indiferencia, en la que el vínculo afectivo es prácticamente nulo. Los distintos niveles dependen más de la distancia física, la edad y la actitud, que de la clase social o raza. Influye también, de manera importante, la calidad de las relaciones familiares y la presencia o no de afinidad de caracteres.

Los abuelos, con relación a los nietos, a veces son cuidadores, compañeros de juego, historiadores — que hablan de su herencia étnica, la historia familiar y las tradiciones-, o bien, consejeros que les guían y asesoran; modelos del envejecimiento y de posibles ocupaciones.... Además de ser una especie de "amortiguadores" entre ellos y los padres (a su vez, hijos de los abuelos), e intervienen para calmar los ánimos y reducir las tensiones. Por todo ello, a menos que los abuelos ejerzan la función de padres, la relación puede ser muy grata.

Estos adultos mayores influyen en sus nietos, de forma indirecta, a través de sus hijos. Así, se constituyen en modelo de habilidades educativas y en un valioso apoyo emocional y económico por su capacidad de otorgar el consejo y la 
información oportunos. Para todo ello, es necesario el respeto mutuo que permita una feliz convivencia - de cerca o de lejos- entre abuelos e hijos casados.

En cuanto a las raíces y tradiciones familiares, los abuelos pueden ser testigos del pasado e inspiradores de sabiduría. De esta manera, se convierten en el enlace con lo bistórico y valioso, para vivificar el presente y proyectarlo al futuro. Todo ello enriquece la cultura y las tradiciones. Por eso, el hombre no sólo el niño, necesita por su misma esencia de la casa, de la familia... y de los abuelos.

Amor de los abuelos, amor agradecido, desprendido, comprensivo y delicadamente exigente. Amor para caminar con sus nietos y con otros miembros de la familia extensa, si así lo desean; amor para ver las cosas con agudeza y profundidad, para conocer el corazón y los pensamientos de los nietos; amor para escucharles y para enseñarles a conversar. Amor de abuelos en y desde un espacio humano que ellos han sabido crear para que los hijos y los nietos encuentren ahí un oasis de cultura y un refugio ${ }^{24}$.

Lo importante es no interrumpir nunca ese diálogo maravilloso entre abuelos y nietos; porque en él se cifra el dar-recibir que sustenta y bace pervivir todo acto de amor verdadero. 


\section{PROPUESTAS EDUCATIVAS PARA VIVIR LA EDAD ADULTA CON MAYOR PLENITUD}

Durante la vida adulta, existen claros indicadores que distinguen a las personas maduras e inmaduras. Vale la pena esforzarse en alcanzar la madurez propia de la etapa que se está viviendo. Para ello se recomienda:

- Resolver, al menos parcialmente, los problemas que se van presentando en cada etapa de la vida, para acercarse a la madurez propia de un adulto.

- Asumir con serenidad los cambios - biológicos, psicológicos y sociales- y encauzarlos de la mejor manera, en beneficio de uno mismo y de la sociedad.

- Cuidar la salud, mediante una dieta adecuada, ejercicio, descanso... y evitar excesos y abandonos, para no sufrir los cambios que no son consecuencia necesaria del natural proceso de envejecimiento.

- Aceptar con serenidad los hechos - esperados e inesperados-, como la jubilación, viudez, enfermedad, muerte de un hijo..., conscientes de la transitoriedad de la vida humana y de que es posible conferir un sentido sobrenatural a los acontecimientos (en el caso de personas creyentes).

- Tener tolerancia a la frustración y confianza en los propios recursos, interiores y exteriores. 
- Estar "en activo" e interesarse por el acontecer y los proyectos de vida de los hijos.

- Propiciar la comunicación con cada hijo; saber cuándo se requiere estar presente y cuándo no; cuándo hablar y cuándo callar.

- Respetar y saber reforzar la actividad educativa de los hijos casados.

- Descubrir lo valioso de la vida presente (no instalarse en el pasado).

- Dar ejemplo de fidelidad al compromiso conyugal, familiar y social.

- Crear, en casa, una atmósfera de cultura, con apoyos literarios y artísticos.

- "Estar" en la vida de los nietos como un amor-refugio, saber y querer escuchar siempre; buscar tiempo para compartirlo.

- Admitir las limitaciones propias de la edad y, a pesar de ellas, cumplir con la propia misión. 


\section{REFERENCIAS BIBLIOGRÁFICAS}

A.A.V.V., Feliz tercera edad., $2^{\mathrm{a}}$ edición., EUNSA., Pamplona., 1990.

BEE, Helen L. y MITCHELL, Sandra K., El desarrollo de la persona en todas las etapas de su vida., $2^{\underline{a}}$ edición., Harla., México., 1987.

CASTILLO, Gerardo., Cautivos en la adolescencia., Oikostau., Barcelona., 1997.

ERIKSON, Erik H., El ciclo vital completado., Paidós., Barcelona., 2000.

HOFFMAN, Lois; PARIS, Scott y HALL Elizabeth. Psicología del desarrollo hoy., Volumen 2., Sexta edición., McGrawHill Interamericana de España, S.A., 1996.

JUAN PABLO II., Carta a las personas mayores., $2^{\text {a }}$ edición., Ediciones Paulinas., México., 2000.

LÓPEZ DE LLERGO, Ana Teresa; CRUZ DE GALINDO, Luz María., Quién fui, quién soy, quién seré. Una guía para educar las etapas de la vida., Editorial Trillas., México., 2003. OLIVEROS F. Otero y ALTAREJOS, José., Los abuelos jóvenes., Editorial Minos, S.A. de C.V., México., 1992.

ORDUÑA ALLEGRINI, María Gabriela., La educación para el desarrollo local. Una estrategia para la participación social., Eunsa., Pamplona., 2000.

POLAINO-LORENTE, Aquilino., Madurez personal y amor conyugal, factores psicológicos y psicopatológicos., Documentos del Instituto de Ciencias para la Familia., Ediciones Rialp., Madrid., 1995. 
RODRÍGUEZ, Segismundo., Salud en el climaterio y menopausia., $2^{\underline{a}}$ reimpresión., Ediciones Dabar., México., 1999.

ROJAS, Enrique., Remedios para el desamor., Editorial Planeta., México., 1991.

ROYO MARÍN, Antonio., Nada te turbe, nada te espante., Editorial Minos, S.A. de C.V., México., 2000. 